\title{
Moodle-Based LMS in The Learning Environment During The COVID-19 Pandemic
}

\author{
Harry Dhika ${ }^{1}$, Fitriana Destiawati ${ }^{2}$, Surajiyo $^{3}$, Musa Jaya ${ }^{4}$ \\ \{dhikatr@yahoo.com ${ }^{1}$,honeyzone86@gmail.com²,surajiyo@unindra.ac.id ${ }^{3}$ \} \\ Universitas Indraprasta PGRI, Indonesia ${ }^{1234}$
}

\begin{abstract}
The education sector was affected by COVID-19 pandemic. Activities can be maximized using e-learning or distance learning so academic activities are not hampered. Almost all learning activities are carried out remotely in an effort to reduce direct social interaction to reduce the wider spread of COVID-19. System integration in the form of utilizing technology such as computers, mobile, and media that can manage to learn electronically can be optimized by using Moodle-based LMS. In this study, the use of Moodle-based LMS aims to maximize a learning system and provide convenience in the use of technology in an effort to deal with the COVID-19 pandemic. The results of this study are to facilitate the use of Moodle-based LMS so that the use of LMS can be maximized. As a material consideration in the use of Moodle-based LMS that can be used in every school in Indonesia.
\end{abstract}

Keywords: Learning Management System; Learning Media; Moodle; E-Learning; COVID-19.

\section{Introduction}

Learning relates to the place and learning process of students and teachers, in the COVID19 pandemic learning activities cannot be done face-to-face or directly, this hinders academic activities in the form of delivery of teaching materials to students. Academic activities in schools can lead to wider dissemination, large-scale social restrictions require that learning activities be carried out independently in each home. Changes to new normal cannot be avoided by anyone, so it requires a readiness to adjust to the COVID-19 or new normal pandemic. The ease of learning at home can be maximized by the use of LMS in its delivery, especially for teachers who have an obligation to provide learning in the difficult times of the COVID-19 pandemic. Utilizing technology as a support for learning activities makes it easy for learning activities at home. E-learning has grown rapidly with various technologies and devices to access learning resources, such as laptops, computers, smartphones, and tablets. Technology has greatly influenced education, learning, and teaching methods [1]. The learning and communication process is more efficient using e-learning which can be used as a source of learning activities, as a means of delivering teaching materials, evaluations, and assessments by teachers for the students concerned.

Information and communication technology (ICT) provides technological solutions to these practical difficulties [2]. With the development of technology and the availability of the internet, this electronic learning system can be implemented well as a better potential in learning 
activities during the COVID-19 pandemic. LMS which we increasingly rely on as a learning tool has considerable potential in the development of knowledge and competency development [3]. LMS provides features that can be used in learning activities that are already available to teachers and students. Students can access and interactively use the various sources of information available to them. E-learning content providers must attract learners with appropriate e-learning content and they must adequately include e-learning services and technology in the e-learning process [4]. Several kinds of factors that make the learning system said to be ineffective are learning models, so there is a need for learning media. Learning media is a tool or method used for the delivery of teaching materials, various learning media can use various methods or methods so that the learning process can take place effectively. With the LMS software can increase student interest in learning activities, especially at home.

Learning activities can be done using Moodle-based e-learning, from the use of the LMS can facilitate learning activities that can optimize the process of understanding and delivery of material even though it is done remotely. This learning method is an effective way to deliver learning material with learning concepts that prioritize ease of access to place and time. Moodle can do activities and other activities such as planning, implementation, and evaluation as a medium for the management of learning activities. Moodle forms the concept of virtual learning, where the distance learning process is a new learning framework for solving educational problems in the COVID-19 pandemic.

\section{Method}

Research conducted based on a qualitative descriptive approach, which examines the status of an object, conditions, systems of thought, function, and perception. Because it does not use calculations in this research study. Literacy studies are also a method in gathering various sources of books, articles and journals, and documents relating to research. The method is a method that requires a lot of activity reading data, analysis, and information that has been collected.

The writing method used in the form of collecting material in the form of theory taken from the analysis results obtained in the application of distance learning or e-learning that is applied by high school teachers in Java-Bali, the object of this study is the teacher and students.

\section{Result and Discussion}

\section{LMS in the Pandemic Period COVID-19}

During the COVID-19 pandemic, learning activities could not be carried out face-to-face or directly, this impeded academic activities in the form of delivery of teaching materials to students. Academic activities in schools can lead to wider dissemination, large-scale social restrictions require that learning activities be carried out independently in each home. Advances in information and communication technology offer new opportunities[5]this analysis begins with the most powerful and commonly used tool for synchronous distance e-learning[6]. In this discussion, the very important role of e-learning tools is the Learning Management System. Distance learning can be accomplished with the presence of an LMS (Learning Management System), an e-learning platform is a software that includes a variety of services that help teachers 
manage their courses[3]applications used in making the learning media process directly as software for the delivery of learning activities programs, facilities provided by the LMS also take the form of learning course management, learning material management, activity management, value management, displaying transcript values, and managing display for elearning. More importantly, this opens up new possibilities for applying pedagogical innovation in an environment where students are expected to function as active, independent, independent and collaborative participants[7].In LMS, mediation involves the acquisition of competencies and communication skills of all teachers and students, and greater concern for the creation of moments of interaction and possible practical applications of collaborative work, that with the learning process happening participative [8]. This application has been given by several schools including Bogor city 4 schools, Bali 2 schools, Surabaya 4 schools, Yogyakarta 6 schools, Semarang 4 schools, Bandung 4 schools. The activities are done in Java bali with excellent results and enthusiasm from the school. The provision of software with compac disk chips is done in the school.

\section{Moodle based LMS}

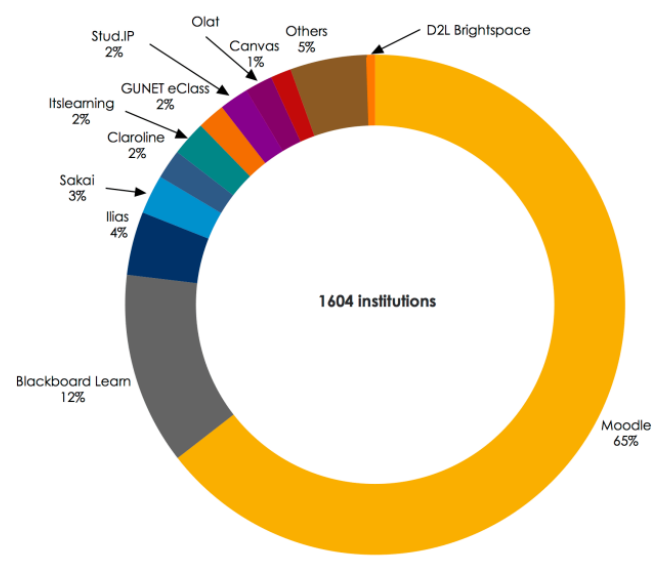

Fig. 1. Percentage of LMS as the Main System.

E-learning is a learning process that focuses on students and teachers interacting directly with each other, both must be connected to the internet and access e-learning to each other together. An e-learning system is a system that provides the services needed to handle all aspects of the course through a single and mobile web interface. These services, for example: (1) course content management, (2) synchronous and asynchronous communication, (3) uploading content, (4) returning student work, (5) peer assessment, (6) administrative students, (7) collection and setting student grades, (8) online questionnaires, (9) online quizzes, (10) tracking devices, etc. [4]. Moodle, an open-source Learning Management System (LMS), collects large amounts of data about student interactions in it, including content, assessment, and communication. Some of this data can be used as a proxy indicator of student involvement, as well as predictors for performance[9]. 
In Moodle, students and teachers can connect to exchange their ideas, information, questions, and answers. This helps them better understand and study learning material via mobile or the web that can be accessed easily through their respective smartphones or computers. There is an increase in education regarding online learning, by emphasizing high concern on the growth of information technology and the use of e-learning this can be an alternative problem-solving in the difficult situation of the COVID-19 pandemic for education. E-learning has proven that usability, effectiveness, and convenience are key factors for acceptance in its use during the COVID-19 pandemic. Thus the use of information and communication technology in education with e-learning through Moodle allows an increase in the effectiveness of education in the COVID-19 pandemic and new normal times.

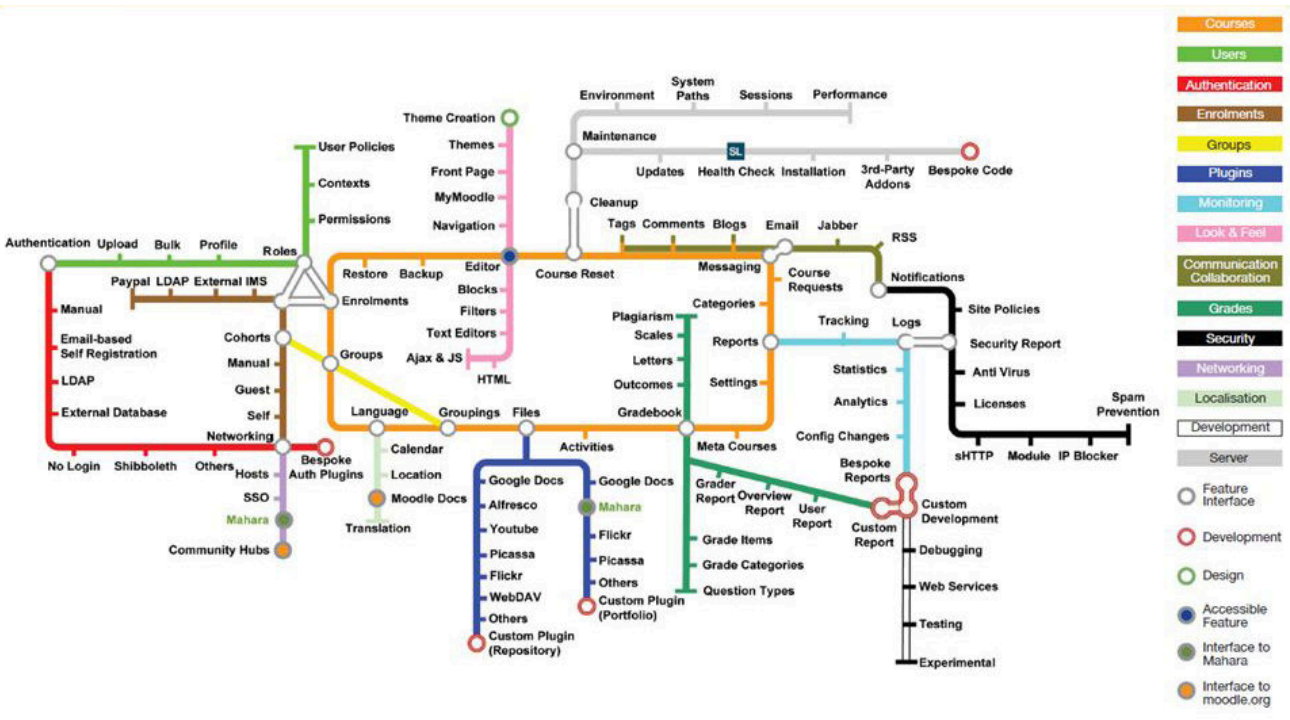

Fig. 2. Administration Map.

Learning media can be said as a tool to convey messages to reduce verbalism and the learning process can take place effectively. Learning media are tools, methods, and techniques used to make communication and interaction effects between teachers and students in the learning process.[10]. By using Moodle, making learning materials easier, quizzes for learning evaluation, and others. The use of LMS has an impact on teacher and student interactions. All content is captured in a computerized database making it easier to process and retrieve data that can be used for learning purposes.

The use of LMS will certainly have a good impact on the existing learning system during the COVID-19 pandemic, this certainly provides great potential in the use of existing technology and communication. Learning is done differently, providing high learning interest, especially for students. Students can access and use it interactively various sources of information available on the internet to support learning. 


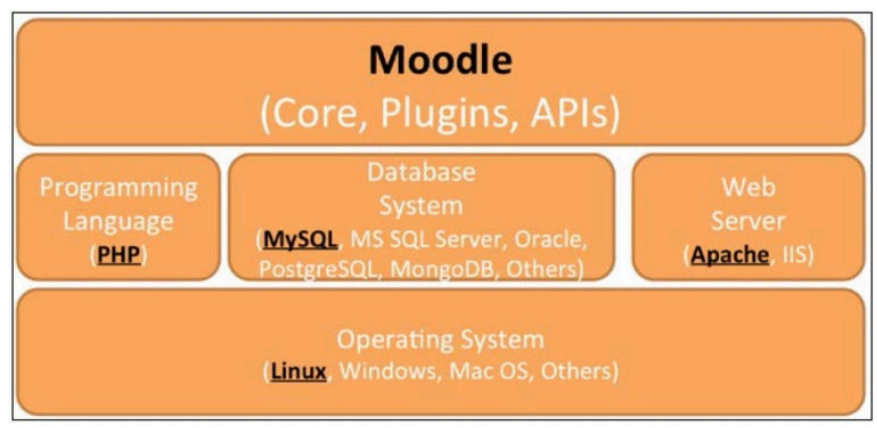

Fig. 3. Moodle Core.

The use of LMS will certainly have a good impact on the learning system during the COVID-19 pandemic or the new normal period, this certainly provides great potential in the use of existing technology and communication. The traditional class method can be changed by the use of e-learning to deal with the COVID-19 pandemic that affects all aspects of life, especially in education.

\section{Moodle Mobile based LMS}

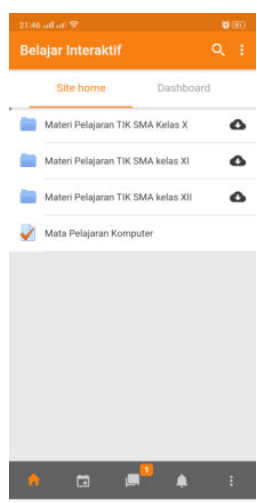

Fig 4. Moodle Mobile Home Page
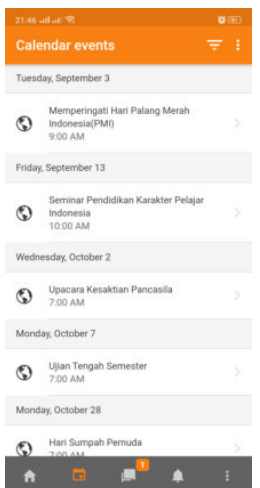

Fig 5. Moodle

Mobile Activity page

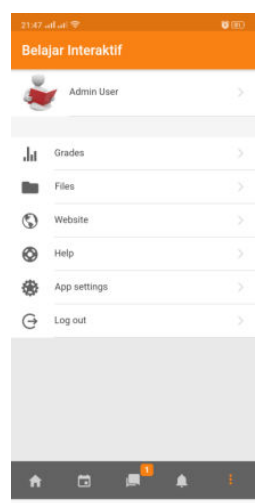

Fig 6. Admin page

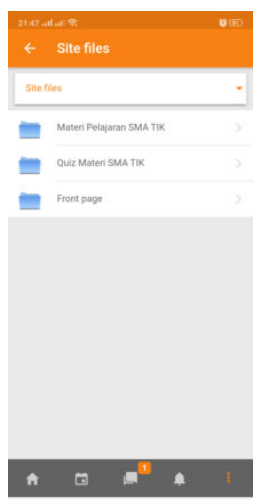

Fig 7. Site Files page

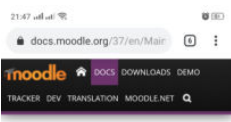

Thoodledocs logm

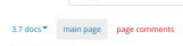

Main page

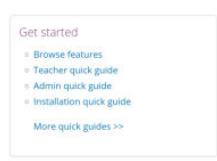

Fig 8. Moodle

Mobile Help page 


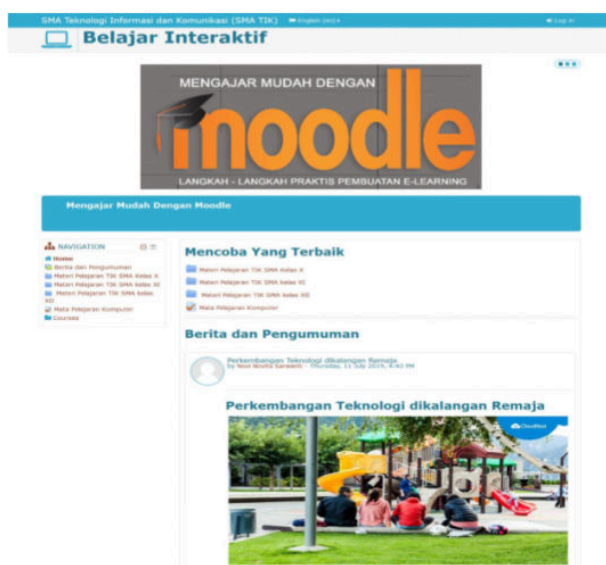

Fig 9. The main page of LMS Moodle

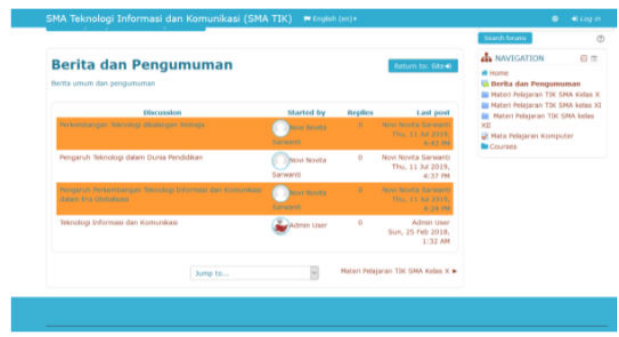

Fig 10. LMS Moodle News and Announcements

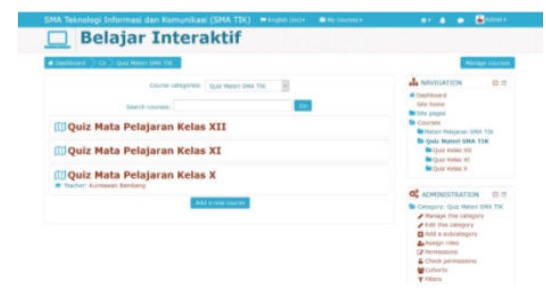

Fig 12. Quiz LMS Moodle

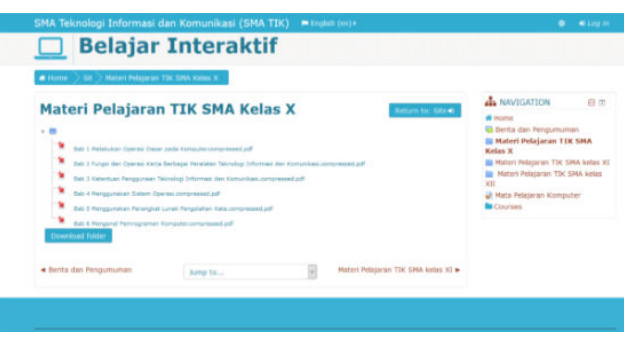

Fig 11. LMS Moodle Learning Materials

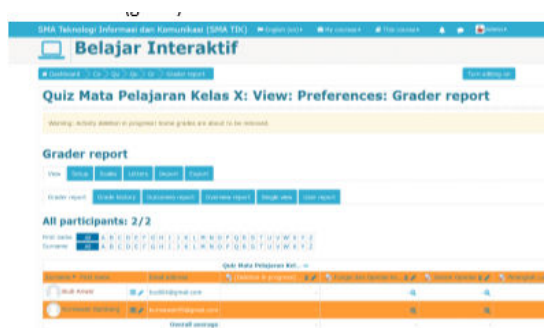

Fig 13. LMS Moodle Grade Grade

\section{Conclusion}

The COVID-19 pandemic period requires schools to apply a learning method based on technology, communication, and information, with the existence of an LMS that can implement electronic learning or called e-learning. Moodle-based LMS can realize an effective and efficient learning system especially when the COVID-19 pandemic takes place, so the use of LMS can be done as a method of new learning. The use of LMS will certainly have a good impact on the learning system during the COVID-19 pandemic or the new normal period, this certainly provides great potential in the use of existing technology and communication. The role of Moodle-based LMS is to create comfortable learning conditions for students and make it 
easier for teachers to provide knowledge and teaching to be better, and more perfect during the COVID-19 pandemic. The software was delivered to schools in the Java and Bali regions, and the Moodle web and mobile models were provided. In school learning using the Learning management system moodle that has been developed and in this case helps learning during the Covid-19 pandemic.

\section{References}

[1] D. Al-Fraihat, M. Joy, R. Masa'deh, and J. Sinclair, "Evaluating E-learning systems success: An empirical study," Comput. Human Behav., vol. 102, no. March 2019, pp. 67-86, 2020.

[2] R. Shah, S. Chakrabarti, A. Sharma, S. Grover, D. Sachdeva, and A. Avasthi, "Participating from homes and offices: Proof-of-concept study of multi-point videoconferencing to deliver group parent training intervention for attention-deficit/ hyperactivity disorder," Asian J. Psychiatr., vol. 41, no. February, pp. 20-22, 2019.

[3] M. Ouadoud, M. Y. Chkouri, and A. Nejjari, "Learning Management System and the Underlying Learning Theories: Towards a new Modeling of an LMS," Int. J. Inf. Sci. Technol. - iJIST, vol. 2 , no. 1, pp. 25-33, 2018.

[4] B. Šumak, M. Heričko, M. Pušnik, and G. Polančič, "Factors affecting acceptance and use of moodle: An empirical study based on TAM," Inform., vol. 35, no. 1, pp. 91-100, 2011.

[5] M. M. Archibald, R. C. Ambagtsheer, M. G. Casey, and M. Lawless, "Using Zoom Videoconferencing for Qualitative Data Collection: Perceptions and Experiences of Researchers and Participants," Int. J. Qual. Methods, vol. 18, pp. 1-8, 2019.

[6] D. F. García, C. Uria, J. C. Granda, F. Suárez, and F. González, “A Functional Evaluation of the Commercial Platforms and Tools for Synchronous Distance e-Learning," Proc. 3rd WSEAS/IASME Int. Conf. Educ. Technol. (EDUTE 2007), pp. 330-335, 2007.

[7] G. Kakasevski, M. Mihajlov, S. Arsenovski, and S. Chungurski, "Evaluating usability in learning management system moodle," Proc. Int. Conf. Inf. Technol. Interfaces, ITI, no. May 2014, pp. 613-618, 2008.

[8] P. C. de Oliveira, C. J. C. de A. Cunha, and M. K. Nakayama, "Learning Management Systems (LMS) and e-learning management: an integrative review and research agenda," J. Inf. Syst. Technol. Manag., vol. 13, no. 2, pp. 157-180, 2016.

[9] D. Yen, -Ting Liu, J.-C. Froissard, D. Richards, and A. Atif, "An enhanced learning analytics plugin for Moodle: student engagement and personalised intervention," Glob. Connect. Digit. enabled. Proc. ascilite 2015, pp. 180-189, 2015.

[10] S. Setiyorini, S. Patonah, and N. A. N. Murniati, "Pengembangan Media Pembelajaran Moodle," J. Penelit. Pembelajaran Fis., vol. 7, no. 2, pp. 156-160, 2017. 